\title{
SCIENTIFIC REP RTS \\ Disturbance and mosquito diversity in the lowland tropical rainforest of central Panama
}

Received: 28 October 2016

Accepted: 28 June 2017

Published online: 03 August 2017
Jose R. Loaiza ${ }^{1,2,3}$, Larissa C. Dutari ${ }^{1}$, Jose R. Rovira ${ }^{1,2}$, Oris I. Sanjur ${ }^{2}$, Gabriel Z. Laporta ${ }^{4,5}$, James Pecor 6 , Desmond H. Foley ${ }^{6}$, Gillian Eastwood ${ }^{7}$, Laura D. Kramer ${ }^{7}$, Meghan Radtke ${ }^{8}$ \& Montira Pongsiri ${ }^{8}$

The Intermediate Disturbance Hypothesis (IDH) is well-known in ecology providing an explanation for the role of disturbance in the coexistence of climax and colonist species. Here, we used the IDH as a framework to describe the role of forest disturbance in shaping the mosquito community structure, and to identify the ecological processes that increase the emergence of vector-borne disease. Mosquitoes were collected in central Panama at immature stages along linear transects in colonising, mixed and climax forest habitats, representing different levels of disturbance. Species were identified taxonomically and classified into functional categories (i.e., colonist, climax, disturbance-generalist, and rare). Using the Huisman-Olff-Fresco multi-model selection approach, IDH testing was done. We did not detect a unimodal relationship between species diversity and forest disturbance expected under the IDH; instead diversity peaked in old-growth forests. Habitat complexity and constraints are two mechanisms proposed to explain this alternative postulate. Moreover, colonist mosquito species were more likely to be involved in or capable of pathogen transmission than climax species. Vector species occurrence decreased notably in undisturbed forest settings. Old-growth forest conservation in tropical rainforests is therefore a highly-recommended solution for preventing new outbreaks of arboviral and parasitic diseases in anthropic environments.

The intermediate disturbance hypothesis (IDH) is one of the most influential and well-known non-equilibrium hypotheses in ecology, providing an explanation for the role of disturbance in the coexistence of climax and colonist species $^{1}$. The IDH postulates that species diversity is highest at intermediate levels of disturbance and declines at low and high levels of disturbance ${ }^{2}$ (Fig. 1a). Following the development of this hypothesis ${ }^{1}$, several studies observed ecological patterns in agreement with the non-equilibrium maintenance of biological diversity ${ }^{3-8}$. This support, coupled with the intuitive nature of the hypothesis, has led to its popularity and acceptance among ecologists ${ }^{9}$. However, recent studies have indicated weak empirical support for and logical flaws in the IDH ${ }^{10-14}$, which has led to substantial debate regarding the scope of IDH and the definitions underlying $\mathrm{it}^{15-17}$.

IDH provides an explanation for the non-equilibrium maintenance of biological diversity based on the assumption that, without disturbance, climax or disturbance-intolerant species tend to monopolise resources (e.g., space and food), driving less competitive species to local extinction and reducing overall species diversity ${ }^{9}$. Under high disturbance regimes, species diversity is predicted to be low because only colonist species are able to cope with severe levels of habitat degradation. Connell ${ }^{1}$ found that vegetation in a Ugandan forest followed a successional sequence in which species richness increased during early colonising stages and then declined during late successional stages. This pattern has been referred to as the "narrow IDH definition"16. Huston ${ }^{18}$ proposed an extension for this narrow definition and indicated that IDH can also apply more generally to

${ }^{1}$ Instituto de Investigaciones Científicas y Servicios de Alta Tecnología, Edificio 219, Clayton, PO, 0843-01103, Ciudad del Saber, Republic of Panama. ${ }^{2}$ Smithsonian Tropical Research Institute, Panama City, Republic of Panama. ${ }^{3}$ Programa Centroamericano de Maestría en Entomología, Universidad de Panama, Panama, Republic of Panama. ${ }^{4}$ Centro de Engenharia, Modelagem e Ciências Sociais Aplicadas, Universidade Federal do ABC, Santo Andre, SP, Brazil. ${ }^{5}$ Setor de Pós-graduação, Pesquisa e Inovação, Faculdade de Medicina do ABC, Santo Andre, SP, Brazil. ${ }^{6}$ Walter Reed Biosystematics Unit, Smithsonian Institution, Museum Support Center, Suitland, MD, United States. ${ }^{7}$ Wadsworth Center, New York State Department of Health, Slingerlands, NY, United States. ${ }^{8}$ US Environment Protection Agency, Washington DC, United States. Correspondence and requests for materials should be addressed to J.R.L. (email: jloaiza@indicasat.org.pa) or G.Z.L. (email: gabriel.laporta@ufabc.edu.br) 

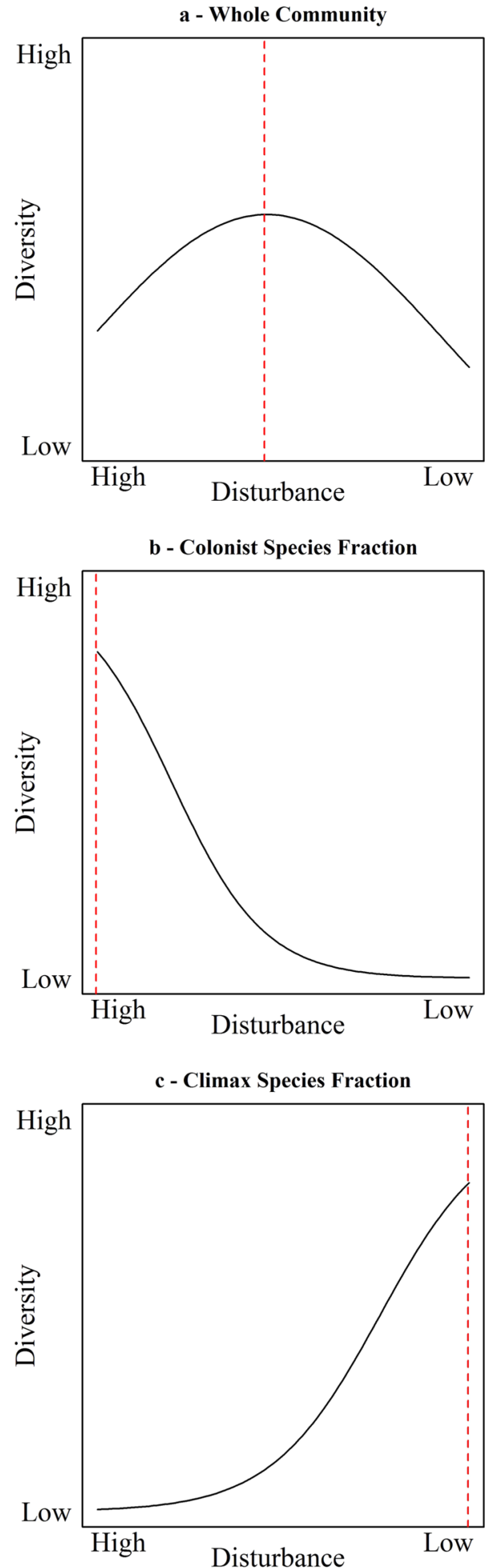

Figure 1. (a) The original IDH proposition made by Connell ${ }^{1}$. The author ${ }^{1}$ considered diversity of a given community to be the highest at intermediate disturbance because of co-occurrence of colonist and climax species in the middle of disturbance gradient. From Connell ${ }^{1}$ we derived theoretically that expected diversity of (b) Colonist species fraction peaks at high disturbance and that of (c) Climax species fraction peaks at low disturbance.

account for disturbance-diversity relationships in non-successional scenarios in tropical rainforests. This definition has been referred to as the "broad IDH definition" ${ }^{15}$. According to this definition, the IDH predicts that disturbance-tolerant species (e.g., colonist) will prevail at high levels of disturbance and that these species will 
be competitively displaced by disturbance-intolerant species (e.g., climax) under low-disturbance regimes. The IDH also states that these two groups of species should be able to coexist at intermediate levels of disturbance, resulting in a unimodal ('hump-shaped') relationship between species diversity and disturbance intensity or frequency (Fig. 1a). Thus, disturbance can act as a reset mechanism whereby populations of competitively dominant species are either periodically subjected to disturbance or subjected to an occasional intense disturbance. As these dominant species are challenged by these disturbance events, critical resources are released for less competitive ('rare') species to use 9 . Several empirical evaluations of the IDH have observed this pattern; $46 \%$ of IDH-related studies have shown significant species diversity relationships with a unimodal shape ${ }^{19}$. However, the value and utility of the broad IDH definition in ecology is contentious ${ }^{10-14}$. Details about this disagreement can be found elsewhere ${ }^{14-16}$.

Herein, we tested IDH expectations empirically using a species-rich assemblage of Neotropical mosquitoes (Diptera: Culicidae) in order to: (1) describe the role of forest disturbance in shaping the mosquito community structure, and (2) identify the ecological processes that increase the risk of vector-borne disease emergence. We hypothesise that mosquito species diversity will peak at intermediate levels of forest disturbance, following IDH (Fig. 1a). This pattern is expected due to an overlap of optimal habitat conditions for both colonist (Fig. 1b) and climax mosquito species (Fig. 1c) in the middle of the disturbance gradient ${ }^{1}$.

Thenceforth, as an alternative to the IDH proposal, we posit that species diversity will peak at climax forest scenarios, provided that old-growth forest habitats harbour a larger variety of larval habitats plus optimal conditions of water temperature and $\mathrm{pH}$ for the interaction of a larger number of species. Next, as a proposition to define the role of forest disturbance on vector-borne disease emergence, we posit that climax and colonist species vary in abundance and somewhat replace each other across a gradient of forest disturbance (e.g., species turn-over), such that within-functional group response to disturbance is more similar than between-functional group response. We also suggest that forest disturbance has a positive effect on the abundance of colonist mosquito species, because it opens opportunities in terms of larval habitat availability and conditions for this group to thrive in altered forest sites. Finally, we link these expectations to the ecological processes that might increase the risk of vector-borne disease emergence, as most colonist mosquito species are likely involved in or are capable of pathogen transmission.

\section{Results}

The role of forest disturbance in shaping mosquito community structure. We empirically tested the assumptions of IDH using 7,839 mosquito larvae belonging to 54 species that were collected from 245 larval sites. These larval habitats were either recipients/containers (natural, artificial) or ground waters. Three categories of forest cover, estimated within a radius of 150-m around each larval habitat, were observed. High forest disturbance occurred in landscape 1 - Las Pavas (2.7-25.5\% forest cover), mid-forest disturbance occurred in landscape 2 - Achiote (39.8-63.1\% forest cover), and low forest disturbance occurred in landscape 3 - Barro Colorado Island (87.2-100\% forest cover), in central Panama. Diversity of mosquito larvae $\left(\mathrm{s}^{2} / \mathrm{n}\right)$ varied across different categories of forest cover (\%), the latter being used here as a proxy of forest disturbance (Fig. 2a,b). Nonetheless, the mid-disturbance peak (e.g., unimodal 'hump-shaped'), expected under the IDH, was not observed, either using the whole mosquito community (i.e., colonist, climax, disturbance-generalist, and rare species) (Fig. 2a) or only Connell's fractions (i.e., colonist \& climax species) (Fig. 2b). Therefore, the outcomes of our analysis using mosquito community data from central Panama do not seem to support the assumptions of IDH. Supplementary results about mosquito species classification into functional groups (colonist, climax, disturbance-intolerant, and rare species) can be found in Supplementary Info - Fig. S1.

Mosquito diversity increased as forest cover increased and vice-versa. Potential underlying mechanisms for the observed effect of forest cover on mosquito species diversity are habitat complexity and habitat constraints (Fig. 2c-f).

Habitat complexity is defined here as forest structure (i.e., number of vegetation layers), which increased from low to high forest cover values (Fig. 2c). Furthermore, colonising forest scenarios were mainly composed of herbaceous stratum, whereas mixed forest scenarios were composed of two or more strata, and then climax forest scenarios were represented by old-growth forest with herbaceous, understory, canopy, and emergent layers of vegetation. Larval habitat composition and availability varied along this gradient of vegetation structural complexity (Fig. 2d). For example, the proportion of fallen leaves increased with high forest cover (11 in low, 12 in mid, 20 in high forest cover), as well as ponds (16 in low, 12 in mid, 31 in high forest cover) and stream margins (17 in low, 19 in mid, 32 in high forest cover). Tree holes were only found in habitats of high forest cover (25) and mid-forest cover (2). Animal footprints were observed in low to mid-forest cover habitats (4 and 8, respectively), but none were observed in high forest cover habitats. Four bromeliads were found at low forest cover, 8 at mid-forest cover, and 16 at high forest cover habitats. Bamboo trees were observed equally in all forest cover habitat categories (3 in low, 3 in mid, 2 in high forest cover).

Habitat constraints, water temperature and $\mathrm{pH}$, measured during the time of mosquito collection in each sampling habitat, varied across the gradient of forest cover (Fig. 2e,f). Values of $\mathrm{pH}$ increased with forest cover, and for this reason, acidic water was found more frequently in low forest cover larval habitats (Fig. 2e). Water temperature decreased when forest cover increased. For this reason, sunlight-exposed waters were more frequently found in low forest cover sampling habitats (Fig. 2f).

The ecological processes that might increase the risk of vector-borne disease emergence. We investigated a possible association between mosquito functional classification and vector status using colonist and climax species, which were the most abundant groups in our study. Evidence of vector incrimination for these species in the Republic of Panama or, if not available, in the Neotropical Region are shown in Supplementary info - Table S1. Out of 10 colonists, 8 were considered vectors of important pathogens ${ }^{20-30}$. Anopheles albimanus, Cq. 

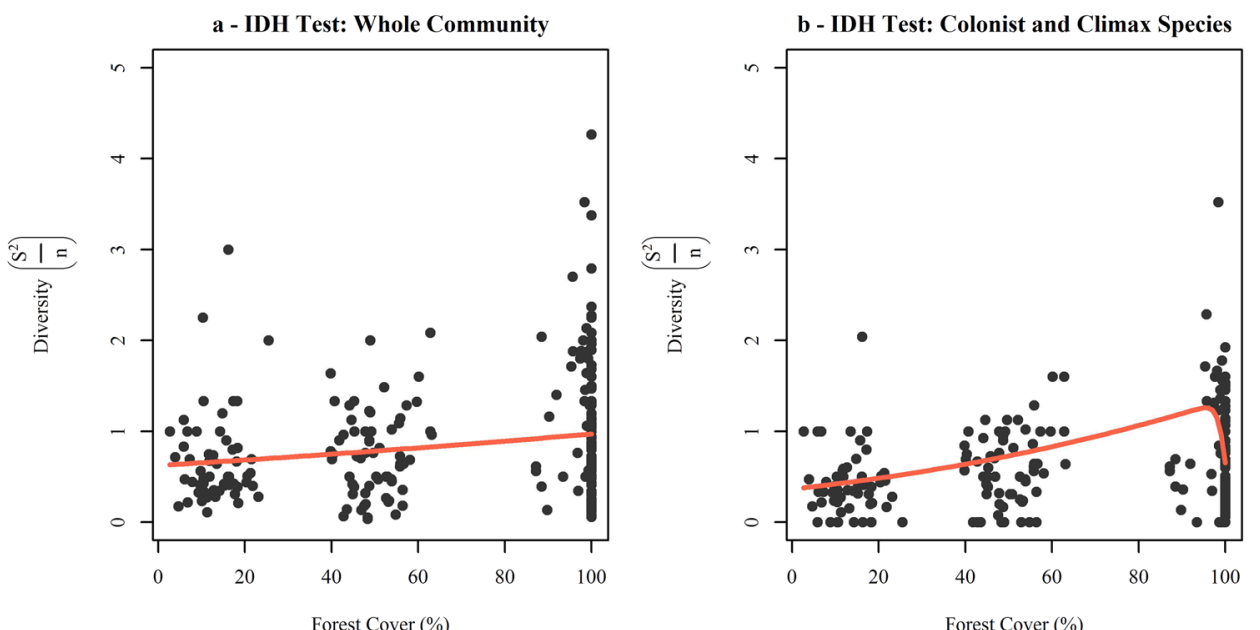

c - Underlying mechanism: Successional Gradient
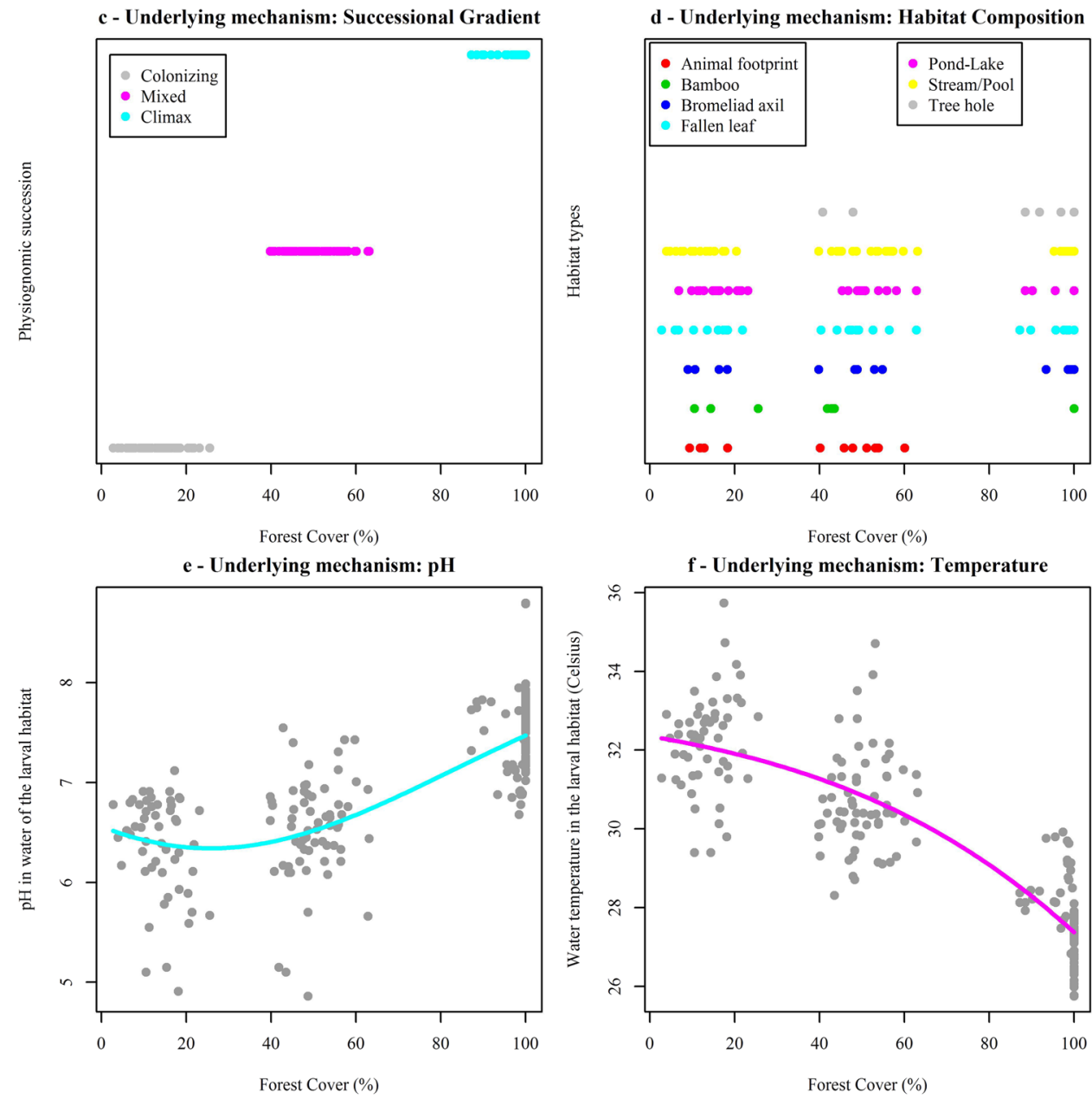

Figure 2. IDH testing. (a) whole community. The best-fitting curve was more plausible than the null model $(\triangle \mathrm{AICc}=1.88$; bootstrap likelihood ratio $=4: 1)$ and meant that mosquito diversity increased as forest cover increased and vice-versa. (b) colonist and climax species (Connell's fractions.). The best-fitting curve was slightly more plausible than the null model $(\triangle \mathrm{AICc}=0.37$; bootstrap likelihood ratio $=2.3: 1)$. Underlying mechanisms: 1) habitat complexity, (c) successional gradient and (d) habitat composition; and 2) larval habitat constraints, (e) $\mathrm{pH}$. The best-fitting curve was more plausible than the null model $(\triangle \mathrm{AICc}=53.2)$ and $(\mathbf{f})$ temperature. The best-fitting curve was more plausible than the null model ( $\triangle \mathrm{AICc}=1,006)$. R program-scripts and full results of multi-model selection are available upon request. 


\begin{tabular}{|l|l|l|l|}
\hline & Vector $=$ yes & Vector $=$ no & Total \\
\hline Colonist & 8 & 2 & 10 \\
\hline Climax & 4 & 8 & 12 \\
\hline Total & 12 & 10 & 22 \\
\hline
\end{tabular}

Table 1. Association of Vector Status (yes, no) with Community Fraction Type (colonist, climax) in a contingency 2 by 2 table. Odds ratio $=8.00(95 \% \mathrm{CI}=1.13,56.79) . X^{2}$ test statistic $=4.791$, $\mathrm{p}$-value $=0.029$ (significant result under the null hypothesis: there is no association; significance level $(\alpha)=0.05$ ).

venezuelensis, Cx. coronator, Cx. nigripalpus, Cx. pedroi, Ma. titillans, Ps. cingulata, and Ps. fexox showed evidence of natural infection in the field and/or high vector competence in the laboratory. Whereas An. albimanus was mentioned as a main vector for malaria parasites in Central America, the other species were listed as vectors for arboviral pathogens that can infect human and/or domestic animals in that region. Coquillettidia nigricans and $C x$. declarator were the only non-vector colonist species of the group. On the other hand, climax species with vector incrimination in the literature were: Ad. squamipennis, An. oswaldoi, An. triannulatus, and Li. durhamii ${ }^{21,22,31-42}$. Aedeomyia squamipennis was considered a vector of enzootic cycles, as it can transmit avian malaria parasites and the Gamboa virus. Both Anopheles oswaldoi and An. triannulatus were considered auxiliary vectors of Plasmodium. A mechanical vector role was considered for $L i$. durhamii, as this species could carry eggs of the human botfly.

The other 8 climax species did not have evidence showing that they could vector pathogens to humans or wildlife, so they were classified as non-vectors. We investigated the most recent reports of vector incrimination for the species in the colonist and climax groupings to avoid temporal bias due to past incriminations that do not hold currently. By applying this strategy, we found that 8 out of 10 colonist mosquito species were incriminated as vectors of pathogens to humans or animals, and 4 out of 12 in the climax fraction. A significant effect $\left(X^{2}\right.$ test statistic $=4.791, \mathrm{p}$-value $=0.029)$ for the association between mosquito functional classification (i.e., colonist or climax species) and vector status (i.e., vectors or non-vectors of pathogens) was found (Table 1). This means that the number of vector species was higher in the colonist category whereas more non-vector mosquito species fit into the climax category. Alternatively, our findings could also mean that vector species were more likely to be colonist than climax mosquito species, while the opposite is also true for non-vector species.

\section{Discussion}

Does mosquito species diversity peak at intermediate levels of forest disturbance (Connell's IDH model vs Fox's criticism)?. In contrast with several previous studies that found patterns supporting the non-equilibrium maintenance of biological diversity ${ }^{3-8}$, Fox ${ }^{14}$ challenged Connell's ${ }^{1}$ IDH model, citing a lack of theoretical support. Connell ${ }^{1}$ stated that at intermediate disturbance levels, competitive exclusion declines, allowing for stable coexistence in a non-equilibrium state. Huston ${ }^{18}$ simulated a Lotka-Volterra competition model with mortality events that mimicked the effects of disturbance and supported Connell's ideas. However, Fox ${ }^{14}$ first cited the lack of evidence that supports competitive exclusion. Fox ${ }^{14}$ also argued that the Huston ${ }^{18}$ model has a subtle outcome. Over the long-term, the increase in average mortality rates cannot produce stable coexistence.

In agreement with the current scientific proposals challenging $\mathrm{IDH}^{11-13}$, we did not find a hump-shaped diversity-disturbance relationship using mosquito larvae diversity and forest cover percentage from the lowland tropical rainforest of central Panama. The present test therefore failed to empirically support IDH. Notwithstanding, the main claims of Fox ${ }^{14}$ pointed to logical flaws in the theoretical rationale of IDH: 1) lack of evidence of competitive displacement, 2) not all species have linear responses to disturbance, and 3) increase in average mortality rates in the long-term, are discussed herein, as follows.

The present study found Connell ${ }^{1}$ fractions - colonist and climax species. Colonist mosquito species were associated with low forest covers at one extreme of forest disturbance gradient, whereas climax species were found at the opposite end. This result resembles the mechanism of coexistence of closely related species at the landscape scale (although they can be spatially segregated at the habitat scale), proposed by Laporta and Sallum ${ }^{43}$, after Juliano ${ }^{44}$.

Similarly, it is shown here that colonist An. albimanus did not co-occur with two climax species, An. oswaldoi and An. triannulatus, at the habitat scale (i.e., larval habitat); although the species coexisted at the landscape scale. It is interesting to note further that both An. oswaldoi and An. triannulatus co-occurred at the larval habitat, but their abundances $(\mathrm{n}=278$ and $\mathrm{n}=138$, respectively) were lower than that of An. albimanus $(\mathrm{n}=602)$. This may indicate that An. oswaldoi and An. triannulatus interact at the microhabitat scale ${ }^{43}$, so that they need to share resources at the surface of the water on those larval habitats where they co-exist (e.g., ponds and stream margins). The partitioning of resources between An. oswaldoi and An. triannulatus is likely due to favourable water $\mathrm{pH}$ and temperature conditions in shared larval habitats with high forest cover. However, when this high forest cover setting is disturbed, departing from $100 \%$ to $20 \%$, it is plausible to assume that both An. oswaldoi and An. triannulatus (i.e., climax) get displaced ${ }^{45}$ by An. albimanus (i.e., colonist), an abundant species in colonising disturbed areas ${ }^{46,47}$. An illustration of the possible competitive displacement of An. albimanus and An. oswaldoi/An. triannulatus mediated by disturbance was made herein.

Another group of closely related species is made up by the colonists $C x$. coronator, $C x$. declarator, and $C x$. nigripalpus, with $C x$. interrogator, another climax species of the same subgenus. These Culex species also showed co-occurrence at the landscape scale and, potentially, competitive displacement. The competitive displacement 
could occur when an assemblage dominated by $C x$. interrogator in high forest cover sites is subjected to disturbance and gets replaced by other dominant Culex (Cux.) species in open areas.

Only 7 species ( 3 Anopheles, 4 Culex (Cux.)) out of 22 colonist and climax species in our dataset fit with a pattern of competitive displacement. This is partly because semi-permanent water habitats species (i.e., Coquillettidia, Mansonia, and Psorophora) mainly occurred in disturbed areas, whereas tree hole and fallen leaves species (i.e., Ae. terrens, An. eiseni, Li. asulleptus, Li. durhamii, Tr. digitatum) were mostly found in forested sites. For these latter species (e.g., Ae. terrens), a disturbance event cannot produce another pair of coexisting species, because tree holes were absent in low forest cover. In relation to the first claim of Fox ${ }^{14}$ regarding lack of evidence for competitive displacement, we state that we could find evidence of competitive displacement, but it does not seem to have a large effect.

Fox ${ }^{14}$ also claimed that not all species have linear responses to disturbance. This claim was supported by our outcomes. Highly abundant species in colonist and climax fractions were found. These species had a linear response to the disturbance gradient. For instance, An. albimanus, Cx. coronator, Ps. cingulata, and Cq. nigricans had peak abundance in the most disturbed areas, and this peak declined towards zero abundance in high forest cover sites. Similarly, Ad. squamipennis, Ae. terrens, An. eiseni, An. trianullatus, and Ur. geometrica had very sharp responses on larval habitats with high forest cover, while their abundances were zero at the other extreme. Notwithstanding, there were other species that did not respond linearly to the disturbance gradient, as claimed by Fox ${ }^{14}$. The colonist Ma. titillans had one peak of high abundance at low forest cover, which is supported by the study of Alfonzo et al. ${ }^{42}$, and another with mid-abundance in the middle of the gradient. The climax species $\mathrm{Li}$. durhamii had two peaks as well, a very high one at high forest cover, supported by Suaza-Vasco ${ }^{41}$, and another with low abundance at intermediate/low forest cover. Additionally, we found five species that can be considered disturbance-generalists, because they had at least two peaks of equal abundances in different forest disturbance categories. This was noticed before for Cx. erraticus by Alfonzo et al. ${ }^{42}$, where they collected $75 \%$ of specimens in open areas and 25\%, in tall undisturbed forest habitats. Finally, we also found a mid-disturbance species, $W y$. simsi, which had a peak of abundance at the intermediate portion of forest disturbance gradient. The finding of a mid-disturbance species in our dataset is interesting because it means that a community dominated by mid-disturbance species would naturally lead to the expected unimodal diversity-disturbance relationship. Considering specific attributes that enabled species to persist at any given disturbance frequency (e.g., refs 48, 49), our data could support the second claim of Fox ${ }^{14}$.

The third claim of Fox ${ }^{14}$ was that disturbance could increase the average mortality rates in the long-term for rare species. The author simulated from a series of population-based differential equations that species with low abundance (rare) were very likely to become extinct in places exposed to frequent disturbances in the long-term. This claim was supported by our data in full. Twenty-six (48\%) of 54 species in our dataset were classified as rare species. Each of these species persists in disturbed areas in a source-sink population dynamics kind of fashion, with Barro Colorado Island as the source of their populations and surrounding areas such as PVAS and ACH as the sink, according to MacArthur and Wilson ${ }^{50}$. Hypothetically, if Barro Colorado Island is exposed to frequent disturbance events, these rare species would probably become locally extinct in the long-term, unless another source for their populations appears.

The fact that we could not empirically support Connell's ${ }^{1}$ IDH pattern with our dataset is related to the claims of Fox ${ }^{14}$. Competitive displacement did not seem to have a large effect. Species had too many peculiar responses to the disturbance gradient, including a group of disturbance-generalists and one mid-disturbance species. In addition, the high number of rare species indicates that they would not coexist in the long-term in a scenario exposed to constant disturbances, because they would probably become extinct.

Mosquito species diversity increased towards relatively undisturbed forest environments. We rejected IDH because mosquito species diversity increased with increasing values of forest cover, rather than peaking in the middle of the forest disturbance gradient. Our results depicted an effect of forest cover on mosquito species diversity, meaning that the number of species increased towards healthier and relatively undisturbed forest sites. Although positive and statistically significant, this effect was small. One analogous example of such a small effect is: an increase of 0 to $50 \%$ forest cover would increase species diversity by 0.2 . However, all 26-rare species ( $48 \%$ of the whole community) were more frequently found in high forest cover.

Underlying mechanisms that could support higher species diversity at high forest cover settings might be habitat complexity and habitat constraints. The former relates to vegetation complexity, which determines the availability and spectrum of different types of larval habitats, whereas the latter is related to chemical composition of the water (i.e., temperature and $\mathrm{pH}$ ) in those habitats. Vegetation complexity tends to decrease from climax to colonising forest scenarios ${ }^{51}$, thus supporting fewer mosquito species along the disturbance axis due to fewer opportunities to develop and coexist. In contrast, habitat constraints tend to increase in the same direction making it harder for climax and rare species to survive in harsh environments ${ }^{51}$. Fluctuations of habitat complexity and constraints lead to variation in larval habitat properties that are more evident at the opposite extremes of the disturbance gradient.

Moreover, higher habitat complexity in undisrupted forest environments might promote niche differentiation due to a higher variety of larval habitats ${ }^{51}$, while lower habitat constraints in these settings may also favour optimum values of temperatures and $\mathrm{pH}$ to yield a larger number of interacting species as larvae in shared aquatic habitats ${ }^{52}$. Our findings further suggest that habitat complexity and constraints are shaped by a successional gradient of forest physiognomic stages, translated into different habitat conditions under three discrete categories of forest cover. Differences in mosquito diversity and abundances across a gradient of forest disturbance could be explained by shifting ecological conditions that affect larval breeding site availability and quality. 
Limitations of the study. The limitations of the present study can be divided into three categories. Ideally, the best study design would match characteristics to cope with these three limitations: (1) The gradient of forest disturbance in this study was not continuous. We had three categories of forest disturbance: a) low forest cover (PVAS), b) medium forest cover (ACH), and c) high forest cover (BCI). In each category, there was a gradient of forest cover, but data were lacking in-between categories. Having more data to fulfil these gaps could help to have a more accurate picture of the effect of forest disturbance on mosquito diversity. (2) Our study design was not a follow-up of successional stages in a single landscape. As our study was a cross-sectional one, the major assumption is that $\mathrm{BCI}$ is an undisturbed scenario for $\mathrm{ACH}$ (a mid-disturbance scenario) and PVAS (a high-disturbance scenario). During the study design, these areas were selected in the same ecosystem (lowland tropical rainforest), so that they could hypothetically represent the same temporal process of disturbance. Using a cross-sectional study to test a temporal-dependent phenomenon such as the successional stages of Connell's ${ }^{1}$ IDH is not only challenging, but this was the main critique of Sheil and Burslem ${ }^{15}$, when they replied to the "IDH should be abandoned" by Fox ${ }^{14}$. According to these authors, replacing space-for-time in such a case would not give the same evidence that Connell ${ }^{1}$ found in successional stages of forest in Uganda. This critique made Fox ${ }^{16}$ lower the tone of his statements and agree with the importance of the narrow Connell-based definition of IDH in order to avoid confounding factors. (3) Our study did not experimentally test the effects of forest disturbance on mosquito diversity. It is not trivial to propose an experiment with an intervention such as 'forest disturbance'. Despite the importance of such an experiment, the opportunities to accomplish this can be very scant. Nevertheless, in places where forest disturbance is out of control, such as in the Brazilian Amazon ${ }^{53}$, one type of intervention could be to compensate landowners for keeping their forest in good shape, and track changes in the mosquito community over time with nearby territories in which landowners would not receive any bonus.

The ecological process that make risky scenarios for vector-borne disease emergence. While it is true that our results did not provide empirical support for IDH in the field of ecology, using this hypothesis and the criticism around it (i.e., by Fox ${ }^{14}$ ), as a framework, allowed us to better understand the role of forest disturbance in mosquito-borne disease transmission. Our considerations here also have implications for disease prevention and control. For instance, Lounibos ${ }^{45}$ discussed the applications of competitive displacement as practice for targeting vector population reduction. Our outcomes suggest that competitive displacement could be applied in the Republic of Panama as well as more broadly (i.e., Colombia, Peru, and Central America) $)^{20,21,46,47}$ to prevent malaria epidemics. This can be achieved by increasing forest cover recovery in highly disturbed areas (i.e., PVAS and $\mathrm{ACH}$ ), favouring the likelihood of auxiliary malarial vectors (i.e., An. oswaldoi/An. triannulatus) ${ }^{36,37}$ over primary ones (i.e., An. albimanus). This control scheme might also be applied to prevent epidemics of arboviral pathogens involving colonists (i.e., $C x$. coronator, $C x$. declarator, and $C x$. nigripalpus) and climax species (i.e., $C x$. interrogator) within the subgenus Culex of Culex.

In terms of disease transmission ${ }^{54-56}$, focusing on Connell's fractions (e.g., climax and colonist mosquito species) gave us the opportunity to investigate the role of these assemblages on disease emergence in relation to forest disturbance. Changes in biodiversity caused by recent landscape disturbance in Panama, or in any other place of the tropical rainforest domain ${ }^{57}$, are likely to impact vector species spectra and status over time ${ }^{58,59}$. We found that the number of mosquito species being incriminated as vectors of pathogens was significantly higher in the colonist fraction than in the climax fraction. Not only was the association colonist-vector species significant, but also it was the most prominent at highly disturbed forest sites, while its likelihood decreased notably towards relatively undisturbed forest settings.

A positive linear response by colonist-vector species to forest disturbance seems to be a tangible process that might increase disease transmission risk in forest-altered tropical areas ${ }^{58}$. 'The colonist-vector fraction' including the malaria vector (i.e., Anopheles albimanus) and zoonotic and bridge vectors of several arboviruses (i.e., Culex pedroi, Culex nigripalpus, Psorophora cingulata, Psorophora ferox, Mansonia titillans, and Coquillettidia venezuelensis) increased in abundance as a function of forest disturbance. According to this view, the so-called spill-over effect might not be a random process, but rather a consequence of forest degradation leading to a higher probability of contact between colonist-vector mosquito species and humans at forest-altered sites. The proportion of different reservoir/hosts existing in forest degraded areas of Panama, will then determine the ultimate disease outcome there, as most mosquito species in forest-altered sites tend to feed opportunistically and upon what is most available nearby. All together, these results suggest a likely role of forest disturbance into vector-borne disease emergence in recently disturbed tropical regions ${ }^{58,59}$, including Panama.

Nevertheless, considering the well-known suite of entomological studies by Dr. Pedro Galindo in the Republic of Panama ${ }^{54-56}$, just to mention a few, and more recently the theoretical insights by Randolph and Dobson ${ }^{60}$, finding vector species in the colonist and climax fractions should be equally expected. This is theoretically anticipated because female mosquitoes of any particular species have the same opportunities to blood-feed upon vertebrate animals that harbour pathogens. This argument might sound compelling, but it has not been supported by prior studies on vector competence. For instance, Turell by himself ${ }^{26}$ and with colleagues ${ }^{24,28,30}$ experimentally tested many mosquito species, thought to be competent transmitters, for infection with different arboviral pathogens, but only partial results could be translated into information on vector incrimination. Cohuet et al. ${ }^{61}$ further stated that pathogens could shape vectors.

If it were true that all mosquito species in the community could transmit pathogens equally efficiently, why are those in the colonist fraction of our study more likely to do so? On the one hand, we could rely upon the work of Myers and Patz ${ }^{58}$, who stated that forest disturbance selects the most abundant species, which could lead to higher contact rates with domestic animals and humans, thus increasing the odds of pathogen transmission on these hosts. On the other hand, we should also consider random genetic processes (e.g., neutral effects ${ }^{62}$ ) as a mechanism that could enhance vector potential at any given time-space. For example, a single mutation event 
Main factor

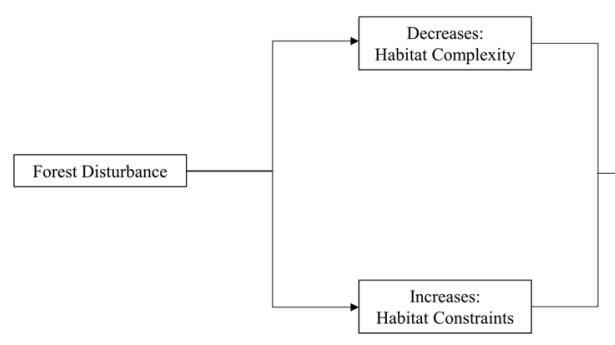

\section{Outcomes}

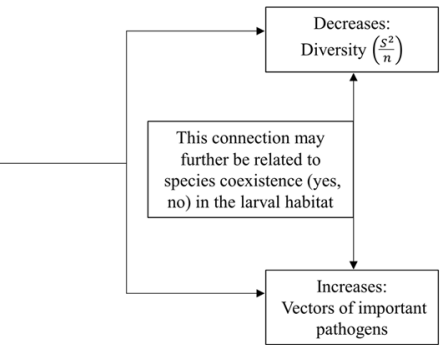

Figure 3. Theoretical synthesis of the results obtained in the present work. The main factor, forest disturbance, decreases habitat complexity and increases habitat constraints. These underlying mechanisms decrease diversity and increase vectors of important pathogens.

made Ae. albopictus a superior vector of Chikungunya virus during several outbreaks across Asia and Europe, ten years ago ${ }^{63}$.

Considering the hypothetical synthesis of our work (Fig. 3), a logical statement is that forest disturbance could cause the overall decline of mosquito species diversity, yet at the same time, it could increase disease transmission risk. Although we did not measure disease risk directly, high abundance of colonist-vector species at immature stages was applied here as a proxy for female mosquito population size in forest altered sites. According to this, the deduction would be that one possible mechanism of interconnection of diversity-disease might be related to species interactions in the larval habitat. The authors are conscious of the limitations of the present work, and so the synthetic diagram in Fig. 3 is only intended to guide future research efforts in this direction.

Randolph and Dobson ${ }^{60}$ made a strong critique about the likely effects of high biodiversity as the buffering element to prevent the emergence of vector-borne disease in relatively undisturbed forest habitats. In our study, colonist-vector species such as An. albimanus (main vector of malaria in Central America ${ }^{20,21,46,47}$ ), Cx. nigripalpus (main vector of St. Louis Encephalitis Virus in the US ${ }^{26}$ ), and $C x$. pedroi (main vector of the Eastern Equine Encephalitis Virus in Peru ${ }^{27}$ ) were conspicuous in highly altered forest settings, while their abundances were almost zero at relatively undisturbed forest sites (i.e., old-growth forest). The fundamental conclusion derived from the field of disease ecology is therefore that old-growth forest conservation in tropical rainforests is a reasonable and highly recommended solution for preventing new outbreaks of arboviral and parasitic diseases in anthropic environments.

\section{Methods}

Study system. This was a cross-sectional and a space-for-time study conducted in the lowland tropical rainforest of central Panama. Herein, we selected three landscapes at different successional stages containing mostly lowland forest and wetland ecosystems ${ }^{64}$ (Fig. 4a). Historically, this area included the Former Panama Canal Zone, a US military territory, with a highly-characterised mosquito fauna due to systematic sampling during the $20^{\text {th }}$ century ${ }^{65}$. Walter Reed Biosystematics Unit (WRBU) Mosquito Catalog ${ }^{66}$ and in-country sources have recorded 286 species of Culicidae in Panama.

Three areas, each expected to having low, medium and high forest disturbances were selected in central Panama for mosquito larvae collection: Barro Colorado Island - BCI $\left(9^{\circ} 16^{\prime} \mathrm{N},-79^{\circ} 84^{\prime} \mathrm{W}\right.$; Fig. $\left.4 \mathrm{~b}\right)$, Achiote - $\mathrm{ACH}\left(9^{\circ} 22^{\prime} \mathrm{N},-80^{\circ} 02^{\prime} \mathrm{W}\right.$; Fig. 4c) and Las Pavas - PVAS $\left(9^{\circ} 09^{\prime} \mathrm{N},-79^{\circ} 87^{\prime} \mathrm{W}\right.$; Fig. $\left.4 \mathrm{~d}\right)$. These areas (herein $\mathrm{BCI}, \mathrm{ACH}$, and PVAS) have different climatic conditions due to their geographic position along a Pacific-Atlantic rainfall gradient ${ }^{67}$. BCI and PVAS are positioned closer to the Pacific Ocean; they are drier (1,793 mm of annual rainfall) and more seasonal, experiencing 7 to 8 months of wet season and 4 to 5 months of dry season. In contrast, $\mathrm{ACH}$ is situated closer to Isthmus' Caribbean coast; it is more humid (3,300 mm of annual rainfall) and less seasonal, experiencing year-round precipitation and lacking a well-defined dry season ${ }^{64,68}$.

Barro Colorado Island (Fig. 4b) is a National Reserve under the custody of the Smithsonian Tropical Research Institute (STRI) since 1923, and is protected by the environmental laws of Panama. The island has a research facility inhabited by a small group of scientists, visitors and administrative personnel, but most of its territory is unoccupied and consists of undisturbed old-growth forest. Hubbell ${ }^{62}$ and colleagues working in BCI proposed the Unified Neutral Theory of Biodiversity, using data collected on plant species abundances.

PVAS and $\mathrm{ACH}$, conversely, are human-altered forest environments that have been gradually colonised during the last 60 years; they have roughly the same number of people, and thus intensity of forest disturbance over these years is thought to be similar. Because of the aforementioned climatic differences between PVAS and ACH, it seems that the latter is more resilient to disturbance because of the higher annual rainfall. This difference can be checked by comparing the satellite imagery taken from the landscape of ACH that shows a later stage of succession (Fig. 4c) in comparison with that observed for PVAS, which resembles an early stage of colonisation (Fig. 4d). Both ACH and PVAS are situated close to a National Park (Fig. 4a); the former borders the Gigante Forest Reserve, whilst the latter borders the San Lorenzo National Park. These landscapes include fragments of old-growth and second-growth forest intermingling with agriculture fields, cattle pastures, and human settlements. The main notion is therefore that they represent a proxy for a hypothetical disturbance scenario of BCI. 


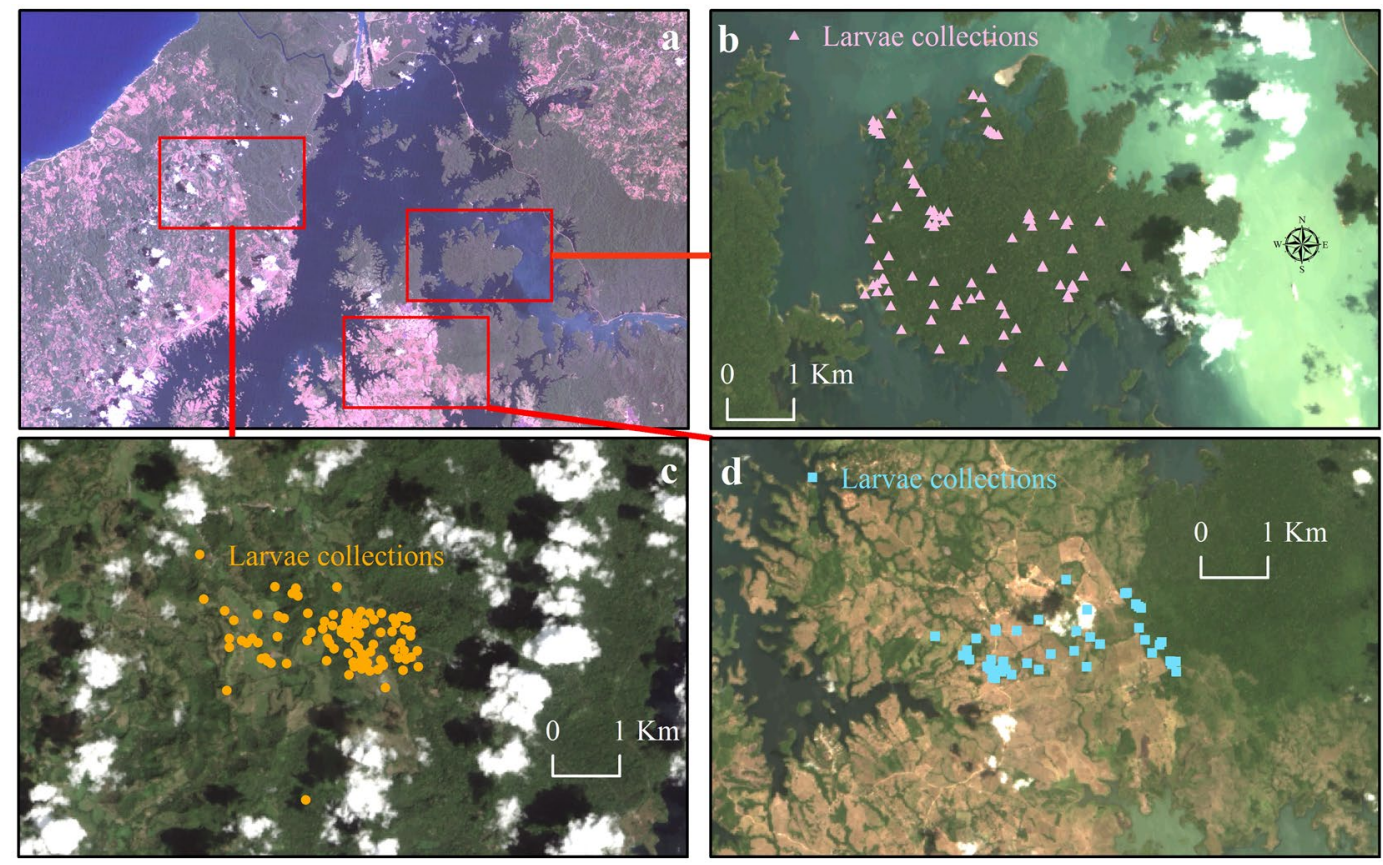

Figure 4. (a) The lowland tropical rainforest of Central Panama, 2000. (b) The Barro Colorado Island, 2014. (c) Achiote, 2016. (d) Las Pavas, 2014. Source: Landsat imagery courtesy of NASA Goddard Space Flight Center and U.S. Geological Survey.

Mosquito sampling and species identification. Immature stages of mosquitoes were collected in linear transects (25 to 30 per each sampling area) of up to 3.5 kilometres $(\mathrm{km})$ long at BCI (mean length $2.88 \pm 0.31$ ), PVAS $(3.36 \pm 0.14)$ and $\mathrm{ACH}(3.37 \pm 0.14)$. All mosquito-breeding sites including phytotelmata and ground water sources encountered at 3-m left and right off transects and 2-m of height were checked for the presence of larvae and pupae. Ground water sources were surveyed using a standard larval dipper ( $350 \mathrm{ml}, 13 \mathrm{~cm}$ diameter per unit) (BioQuip ${ }^{\circledR}$, Rancho Dominguez, CA). Up to 40 dips $(140,000 \mathrm{ml}$ approx.) were taken from each breeding site after ten initial dips to determine positivity. Roots of aquatic vegetation (i.e., mostly Pistia and Eichornia) in stable breeding sites were rinsed with a 10\% solution of Sodium Hydroxide, so that larvae and pupae of Mansonia and Coquillettidia mosquitoes detached themselves and rose to the surface. Furthermore, Phytotelmata breeding sites were surveyed using a $250 \mathrm{ml}$ pipette and a white plastic tray $(25 \times 20 \times 4 \mathrm{~cm})\left(\right.$ BioQuip ${ }^{\circledR}$, Rancho Dominguez, CA), with relatively similar amounts of water being extracted as in-ground breeding sites. Samples were placed into Whirl-Pak ${ }^{\circledR}$ plastic bags $\left(118 \mathrm{ml}, 8 \times 18 \mathrm{~cm}\right.$ ) (BioQuip ${ }^{\circledR}$, Rancho Dominguez, CA) filled approximately $3 / 4$ full of water from their respective habitats and brought to the laboratory in a cooler container. Later, they were sorted to subfamily level, grouped according to instar in different breeding chambers and link-reared to adult.

Each larval breeding site was photographed with a digital camera and characterised according to environmental features using a standard data collection form ${ }^{66}$. This form included a set of discrete and continuous environmental variables, including degree of shade, water stability, presence or absence of vegetation as well as $\mathrm{pH}$ and temperature $\left({ }^{\circ} \mathrm{C}\right)$ of the water, respectively. Water $\mathrm{pH}$ and water temperature were measured with a high range HI 98130 Waterproof $\mathrm{pH} /$ Conductivity/TDS Tester (Hanna ${ }^{\circledR}$ instruments, Woonsocket, RI). In addition, geographic coordinates (e.g., values of latitude and longitude) for each larval sampling site were recorded using a hand held Global Positioning System (GPS) unit (Garmin ${ }^{\circledR}$ International, Olathe, KS), set to the WGS84 datum and geo-referenced in a Landsat ${ }^{\mathrm{TM}} 8$ OLI satellite image ${ }^{69}$. The bands Red (B4), Green (B3), and Blue (B2) were used to make a RGB composition that was pan-sharpened with the multispectral band (B8) in ArcMAP ${ }^{\mathrm{TM}}$ 10.3.1 (ESRI, Redlands, CA), resulting in a 15-m spatial resolution image above which geo-referenced coordinates were represented. This allowed us to estimate the percentage of forest cover within a 150-metre radius around each sampling unit (i.e., larval sampling sites). Sampling transects in PVAS and ACH encompassed areas of low (e.g., $>35 \%$ ), intermediate (e.g., $>35 \%$ and $<65 \%$ ) and high forest cover (e.g., $>65 \%$ ) in similar proportions, while $\mathrm{BCI}$ comprised high forest cover points (e.g., old-growth forest). Mosquito larval collections were carried out every other month from August 2011 to November 2012 in BCI; sampling in PVAS and ACH was conducted in the same fashion from May 2012 to January 2013. A representative portion of the data sets analysed in the present work can be obtained by request from the VectorMap portal ${ }^{70}$

Reared adult mosquito samples were pinned in cardboard triangles, labelled with a unique code/number, and identified using diagnostic morphological characters ${ }^{71-73}$. Species verification was achieved using male genitalia and fourth-instar larval skin preparations following the protocols listed by Thomas Gaffigan and James Pecor ${ }^{66}$. Voucher specimens were deposited at INDICASAT AIP, and also at the University of Panama. In addition, two legs were removed from well-preserved specimens for molecular species confirmation and analysis using the Barcoding region (5' prime region of the Cytochrome C Oxidase Subunit One mitochondrial gene [CO1] $)^{74}$. A 
total of 289 samples for 52 species, initially identified on morphological characters, were randomly taken from the total collected and processed molecularly to rule out potential confounding effects of morphology on the estimation of species diversity. DNA extraction, PCR-amplification and sequencing were done at STRI following standard protocols ${ }^{75}$. We built a neighbour-joining (NJ) tree using CO1 sequences in MEGA v.5.1 ${ }^{76}$ with Kimura 2 parameter (K2P) distances, and bootstrapped the topology with 500 replicates to obtain branch support. We also created a NJ tree using an expanded dataset combining our CO1 sequences along with additional CO1 sequences from GenBank $k^{77}$ and from The Barcode of Life Data System (bold) ${ }^{74}$.

Data analysis strategy. The sampling unit in the analysis was the larval habitat or larval sampling sites and for each analysis the sample size used was $\mathrm{N}=245$, which corresponded to the total number of sample sites from BCI (99), PVAS (46), and ACH (100). The strategy of combining data was three-fold: (1) in relation to the experimental design, which considered a wide range of forest cover values, and then all the sites sampled belonged to a gradient of disturbance, (2) pooling the data resulted in the same outcomes when analysing data from PVAS and $\mathrm{ACH}$ separately, and (3) pooled samples from PVAS, ACH and BCI allowed us to increase statistical power of each analysis and to detect deviations from randomness, making possible generalisations about central Panama including pristine and heterogeneous landscapes.

Mosquito species classification into functional fractions and IDH testing. Each mosquito species in the community was classified as colonist, climax, disturbance-generalist or rare, by employing a multi-model selection analysis for each species' specific-abundance and forest cover. This resulted in a total of $7 * 54=378$ models. For the sake of simplicity, we did not show herein all the AICc difference and bootstrap model checking results. Notwithstanding, all these results can be made available upon request.

We first classified mosquito species into distinct functional groups, following Connell ${ }^{1}$. This was done by examining mosquito species-specific abundance response to different levels of forest disturbance, measured by variations in forest cover proportion (\%). As a result of this, we divided the mosquito assemblage into colonist (i.e., disturbance-tolerant; Fig. 1b) or climax (i.e., disturbance-intolerant; Fig. 1c) groupings. Furthermore, species that did not respond to disturbance were classified as disturbance-generalists, and species with low abundance ( $<5 \%$ of occurrence) were classified as rare species.

This classification was performed by using the same approach applied by Laporta and Sallum ${ }^{43}$. A multi-model selection scheme was used to fit a specific regression curve to the following data: larval abundance of a given mosquito species gathered from habitats with different proportions of forest cover. Huisman-Olff-Fresco models with extensions compete against each other during this multi-model selection approach (Supplementary InfoFig. S2) ${ }^{78}$. Model 1 is the null model (the null hypothesis). Models 2-7 are the alternative hypotheses. Model 2 and Model 3 indicate that larval abundance correlates monotonically (i.e., linearly) with forest cover values. Model 4 and Model 5 indicate that larval abundance has a unimodal correlation with forest cover, while Models 6 and 7 indicate that larval abundance has a bimodal correlation with forest cover. The best curve was selected based on a specific set of criteria. The selected model was based on maximum likelihood estimates and the least number of parameters, i.e., the Akaike Information Criteria corrected for small samples (AICc) ${ }^{78}$. Bootstrap model checking was performed to evaluate the robustness of each selected model simulated 100 times $^{78}$.

We tested IDH assumptions by running the same multi-model selection scheme used formerly (Supplementary Info - Fig. S2). This time, the expectation was that estimates of mosquito diversity in response to different levels of forest disturbance would fit the regression curve in Model 4, thus supporting the expected outcome of IDH (i.e., 'hump-shaped'). First, we tried to fit data from the whole mosquito community to Model 4, and then, we fit data to the same model, but only from the two fractions proposed by Connell ${ }^{1}$. Forest cover was the independent variable and mosquito diversity, the dependent variable. These variables were measured at the scale of the larval habitat, i.e., the micro-habitat scale ${ }^{43}$. In each larval habitat, we estimated the $\alpha$-diversity ${ }^{79}$, herein referred to as diversity. The estimation of diversity followed the procedures adopted by Gotelli and Colwell ${ }^{80}$. The richness of species can increase because of the total abundance, so an adjustment is necessary, named rarefaction ${ }^{80}$. To our data, we applied this idea and then used the squared richness divided by total abundance in each larval habitat.

Causative mechanisms of ecological and epidemiological outcomes. Underlying mechanisms or possible co-factors that go along with forest disturbance and could therefore be related to the observed pattern of mosquito diversity were also assessed here. These co-factors were: 1) successional gradient of forest types, 2) larval habitat types, 3) water $\mathrm{pH}$ and 4) water temperature. All these co-factors were assessed in each larval habitat. Successional gradient of forest and larval habitat types were associated with forest cover variations utilising standard summarising statistics and graphics. Correlations between larval water $\mathrm{pH}$ and forest cover and larval water temperature and forest cover were assessed by applying the multi-model (Supplementary Info - Fig. S2) selection approach described earlier.

The vector status of each of the colonist and climax species was investigated by searching the specialised recent literature in Pubmed (5 years or more). We tried, when available, to select evidence in published papers in the last five years to decrease temporal bias. The selection was based on evidence of vector incrimination from either natural infection in field studies or vector competence in laboratory assays. Ecological studies that aimed to understand the vector role in vector-borne disease dynamics were also considered, when the authors discussed the specific role as vector for the studied species. Evidence with a low connection to vector role was not considered. For instance, a species that was positive for arboviral infection in the laboratory, but only one specimen was infected out of 30 tested was not considered a vector. Another species that was found naturally infected with non-infectious stage of a known human pathogen or with the infectious stage of a non-vertebrate pathogen was not considered a vector. An important pathogen was defined herein as any protozoa, microfilaria, and/or arbovirus that could cause clinical infection in a host, either human or animal. 
The association between colonist/climax and vector/non-vector was performed by employing a 2 by 2 contingency table. We estimated the odds ratio (OR) with a 95\% confidence interval, in which the null hypothesis is $\mathrm{OR}=1$ (null effect). A $X^{2}$ test was also performed to test the following null hypothesis: $\mathrm{H}_{0}$, there is no association. The significance level adopted was 0.05 .

\section{References}

1. Connell, J. H. Diversity in tropical rain forests and coral reefs. Science 199, 1302-1309 (1978).

2. Molino, J. F. \& Sabatier, D. Tree diversity in tropical rain forests: a validation of the intermediate disturbance hypothesis. Science 294 , 1702 (2001).

3. Hutchinson, G. E. The paradox of the plankton. Am. Nat. 95, 137-145 (1961).

4. Dayton, P. K. Competition, disturbance, and community organization: the provision and subsequent utilization of space in a rocky intertidal community. Ecol. Monogr. 41, 351-389 (1971).

5. Wiens, J. A. On competition and variable environments. Am. Sci. 65, 590-607 (1977).

6. Sousa, W. P. The role of disturbance in natural communities. Annu. Rev. Ecol. Syst. 15, 353-391 (1984).

7. Kneidel, K. A. Competition and disturbance in communities of carrion-breeding Diptera. J. Am Ecol. 53, 849-865 (1984).

8. Townsend, C. R., Scarsbrook, M. R. \& Dolédec, S. The intermediate disturbance hypothesis, refugia, and biodiversity in streams. Limnol. Oceanogr. 42, 938-949 (1997).

9. Sheil, D. \& Burslem, D. F. R. P. Disturbing hypotheses in tropical forests. Trends Ecol. Evol. 18, 18-26 (2003).

10. Hubbell, S. P. et al. Light-gap disturbance, recruitment limitation, and tree diversity in a Neotropical forest. Science 283, 554-557 (1999).

11. Mackey, R. L. \& Currie, D. J. The diversity-disturbance relationship: is it generally strong and peaked? Ecology 82, 3479-3492 (2001).

12. Hughes, A. R., Byrnes, J. E., Kimbro, D. L. \& Stachowicz, J. J. Reciprocal relationships and potential feedbacks between biodiversity and disturbance. Ecol. Lett. 10, 849-864 (2007).

13. Bongers, F., Poorter, L., Hawthorne, W. D. \& Sheil, D. The intermediate disturbance hypothesis applies to tropical forests, but disturbance contributes little to tree diversity. Ecol. Lett. 12, 798-805 (2009).

14. Fox, J. W. The intermediate disturbance hypothesis should be abandoned. Trends Ecol. Evol. 28, 86-92 (2013a).

15. Fox, J. W. The intermediate disturbance hypothesis is broadly defined, substantive issues are key: a reply to Sheil and Burslem. Trends Ecol. Evol. 28, 572-573 (2013b).

16. Sheil, D. \& Burslem, D. F. Defining and defending Connell's intermediate disturbance hypothesis: a response to Fox. Trends Ecol. Evol. 28, 571 (2013).

17. Huston, M. A. Disturbance, productivity, and species diversity: empiricism versus logic in ecological theory. Ecology 95 , 2382-2396 (2014).

18. Huston, M. A. A general hypothesis of species diversity. Am. Nat. 113, 81-101 (1979).

19. Kershaw, H. M. \& Mallik, A. U. Predicting plant diversity response to disturbance: applicability of the intermediate disturbance hypothesis and mass ratio hypothesis. Crit. Rev. Plant. Sci. 32, 383-395 (2013).

20. Conn, J., Quinones, M. \& Povoa, M. Phylogeography, vectors, and transmission in Latin America (ed. Manguin, S), Ch. 5, 145-149 (InTech Open Access Publisher, 2013).

21. Calzada, J. E. et al. Characterization of a recent malaria outbreak in the autonomous indigenous region of Guna Yala, Panama. Malar. J. 17, 459 (2015).

22. Eastwood, G. et al. Enzootic arbovirus surveillance in forest habitat and phylogenetic characterization of novel isolates of Gamboa Virus in Panama. Am. J. Trop. Med. Hyg. 94, 786-793 (2016).

23. Aitken, T. H., Downs, W. G., Anderson, C. R., Spence, L. \& Casals, J. Mayaro virus isolated from a Trinidadian mosquito. Mansonia venezuelensis. Science 131, 986 (1960).

24. Turell, M. J. et al. Vector competence of Peruvian mosquitoes (Diptera: Culicidae) for epizootic and enzootic strains of Venezuelan equine encephalomyelitis virus. J. Med. Entomol. 37, 835-839 (2000).

25. Alto, B. W., Connelly, C. R., O’Meara, G. F., Hickman, D. \& Karr, N. Reproductive biology and susceptibility of Florida Culex coronator to infection with West Nile virus. Vector Borne Zoonotic Dis. 14, 606-614 (2014).

26. Turell, M. J. Vector competence of three Venezuelan mosquitoes (Diptera: Culicidae) for an epizootic IC strain of Venezuelan equine encephalitis virus. J. Med. Entomol. 36, 407-409 (1999).

27. Day, J. F. \& Stark, L. M. Frequency of Saint Louis encephalitis virus in humans from Florida, USA: 1990-1999. J. Med. Entomol. 37, 626-633 (2000).

28. Turell, M. J. et al. Susceptibility of Peruvian mosquitoes to eastern equine encephalitis virus. J. Med. Entomol. 45, 720-725 (2008).

29. Burton, G. J. Attack on the vector of filariasis in British Guiana. Public. Health. Rep. 79, 137-143 (1964).

30. Turell, M. J. et al. Potential for mosquitoes (Diptera: Culicidae) from Florida to transmit Rift Valley fever virus. J. Med. Entomol. 50, 1111-1117 (2013).

31. Loaiza, J. R. \& Miller, M. J. Seasonal pattern of avian Plasmodium-infected mosquitoes and implications for parasite transmission in central Panama. Parasitol. Res. 112, 3743-3751 (2013).

32. Alencar, J. et al. Flight height preference for oviposition of mosquito (Diptera: Culicidae) vectors of sylvatic yellow fever virus near the hydroelectric reservoir of Simplício, Minas Gerais, Brazil. J. Med. Entomol. 50, 794-795 (2013).

33. Schiemann, D. J., Pinzón, M. L. \& Hankeln, T. Anthropophilic Anopheles species composition and malaria in Tierradentro, Córdoba, Colombia. Mem. Inst. Oswaldo Cruz. 109, 384-387 (2014).

34. Ahumada, M. L. et al. Spatial distributions of Anopheles species in relation to malaria incidence at 70 localities in the highly endemic Northwest and South Pacific coast regions of Colombia. Malar. J. 15, 407 (2016).

35. Pinault, L. L. \& Hunter, F. F. New highland distribution records of multiple Anopheles species in the Ecuadorian Andes. Malar. J. 10, $236(2011)$

36. Dusfour, I., Issaly, J., Carinci, R., Gaborit, P. \& Girod, R. Incrimination of Anopheles (Anopheles) intermedius Peryassú, An. (Nyssorhynchus) nuneztovari Gabaldón, An. (Nys.) oswaldoi Peryassú as natural vectors of Plasmodium falciparum in French Guiana. Mem. Inst. Oswaldo Cruz. 107, 429-432 (2012).

37. Rios-Velásquez, C. M. et al. Experimental Plasmodium vivax infection of key Anopheles species from the Brazilian Amazon. Malar. J. 12, 460 (2013).

38. Manrique-Saide, P. et al. Incrimination of the mosquito, Aedes taeniorhynchus, as the primary vector of heartworm, Dirofilaria immitis, in coastal Yucatan, Mexico. Med. Vet. Entomol. 24, 456-460 (2010).

39. Salas, R. A. et al. Ecological studies of enzootic Venezuelan equine encephalitis in north-central Venezuela, 1997-1998. Am. J. Trop. Med. Hyg. 64, 84-92 (2001).

40. Marchi, M. J., Pereira, P. A., de Menezes, R. M. \& Tubaki, R. M. New records of mosquitoes carrying Dermatobia hominis eggs in the state of São Paulo, southeastern Brazil. J. Am. Mosq. Control Assoc. 28, 116-118 (2012).

41. Suaza-Vasco, J. et al. The Sabethines of Northern Andean Coffee-Growing Regions of Colombia. J. Am. Mosq. Control. Assoc. 31, 125-134 (2015)

42. Alfonzo, D. et al. Ecological characterization of the aquatic habitats of mosquitoes (Diptera: Culicidae) in enzootic foci of Venezuelan equine encephalitis virus in western Venezuela. J. Med. Entomol. 42, 278-284 (2005). 
43. Laporta, G. Z. \& Sallum, M. A. Coexistence mechanisms at multiple scales in mosquito assemblages. BMC Ecol. 14, 30 (2014).

44. Juliano, S. A. Species interactions among larval mosquitoes: context dependence across habitat gradients. Annu. Rev. Entomol. 54, 37-56 (2009).

45. Lounibos, L. P. Competitive replacement and reduction. J. Am. Mosq. Contr. Assoc. 23, 276-282 (2007)

46. Lainhart, W. et al. Epidemic and non-epidemic hot spots of malaria transmission occur in indigenous comarcas of Panama. PLoS Negl. Trop. Dis. 10, e0004718 (2016)

47. Loaiza, J. R., Bermingham, E., Scott, M. E., Rovira, J. R. \& Conn, J. E. Species composition and distribution of adult Anopheles (Diptera: Culicidae) in Panama. J. Med. Entomol. 45, 841-851 (2008).

48. Barros, F. S., Arruda, M. E., Gurgel, H. C. \& Honório, N. A. Spatial clustering and longitudinal variation of Anopheles darlingi (Diptera: Culicidae) larvae in a river of the Amazon: the importance of the forest fringe and of obstructions to flow in frontier malaria. Bull. Entomol. Res. 101, 643-658 (2011).

49. Barros, F. S. \& Honório, N. A. Deforestation and Malaria on the Amazon Frontier: Larval Clustering of Anopheles darlingi (Diptera: Culicidae) Determines Focal Distribution of Malaria. Am. J. Trop. Med. Hyg. 93, 939-953 (2015).

50. MacArthur, R. H. \& Wilson, E. O. The theory of island biogeography 22-40 (Princeton University Press 1967).

51. Tokeshi, M. Species Coexistence: Ecological and Evolutionary Perspectives 146-182 (Wiley-Blackwell 1998).

52. Rejmánková, E., Grieco, J., Achee, N. \& Roberts, D. R. Anopheles mosquitoes - new insights into malaria vectors, (ed. Manguin, S.), Ch. 13, 397-446, (InTech Open Access Publisher, 2013).

53. Nobre, C. A. et al. Land-use and climate change risks in the Amazon and the need of a novel sustainable development paradigm. PNAS 113, 10759-10768 (2016).

54. Galindo, P., Trapido, H., Carpenter, S. J. \& Blanton, F. S. The abundance cycles of arboreal mosquitoes during six years at a sylvan yellow fever locality in Panama. An. Entomol. Soc. Am. 49, 543-547 (1956).

55. Galindo, P., Srihongse, S., De Rodaniche, E. \& Grayson, M. A. An ecological survey for arboviruses in Almirante, Panama, 19591962. Am. J. Trop. Med. Hyg. 15, 385-400 (1966).

56. Galindo, P. \& Grayson, M. A. Culex (Melanoconion) aikenii: natural vector in Panama of endemic Venezuelan encephalitis. Science 172, 594-5 (1971).

57. Gibson, L. et al. Primary forests are irreplaceable for sustaining tropical biodiversity. Nature 478, 378-381 (2011).

58. Myers, S. S. \& Patz, J. A. Emerging threats to human health from global environmental change. Annu. Rev. Environ. Resour. 34, 223-252 (2009).

59. Laporta, G. Z., Prado, P. I. K. L., Kraenkel, R. A., Coutinho, R. M. \& Sallum, M. A. M. Biodiversity can help prevent malaria outbreaks in tropical forests. PLoS Negl. Trop. Dis. 7, e2139 (2013).

60. Randolph, S. \& Dobson. Pangloss revisited: a critique of the dilution effect and the biodiversity-buffers-disease paradigm. Parasitology 1-17 (2012).

61. Cohuet, A., Harris, C., Robert, V. \& Fontenille, D. Evolutionary forces on Anopheles: what makes a malaria vector? Trends Parasitol. 26, 130-130 (2010)

62. Hubbell, S. P. The Unified Neutral Theory of Biodiversity and Biogeography (Princeton University Press, 2001).

63. Enserink, M. Chikungunya: No Longer a Third World Disease. Science 318, 1860-1861 (2007).

64. Windsor, D. M. Climate and moisture variability in a tropical forest: long-term records from Barro Colorado Island. Panama (1990).

65. Foley, D. H., Rueda, L. M. \& Wilkerson, R. C. Insight into global mosquito biogeography from country species records. J. Med. Entomol. 44, 554-567 (2007).

66. WRBU - The Walter Reed Biosystematics Unit. Available at: http://www.wrbu.org/. (Accessed: 4th August 2014).

67. Lachniet, M. S., Patterson, W. P., Burns, S., Asmerom, Y., \& Polyak, V. Caribbean and Pacific moisture sources on the Isthmus of Panama revealed from stalagmite and surface water gradients. Geophys. Res. Lett. 34 (2007).

68. Poveda, G., Waylen, P. R. \& Pulwarty, R. S. Annual and inter-annual variability of the present climate in northern South America and southern Mesoamerica. Palaeogeograp, Palaeoclimatol, Palaeoecol 234, 3-27 (2006).

69. Landsat 8 - U. S. Geological Survey. Available at: http://landsat.usgs.gov/landsat8.php. (Accessed: 10th February 2017).

70. VectorMap. Available at: http://www.mosquitomap.org/. (Accessed: 7th March 2014).

71. Pecor, J. E., Mallampalli, V. L., Harbach, R. E., \& Peyton, E. L. Catalog and illustrated review of the subgenus Melanoconion of Culex (Diptera: Culicidae). Contrib. Am. Entomol. Inst. (1992).

72. Wilkerson, R. C., Strickman, D. \& Litwak, I. B. T. R. Illustrated key to the female anopheline mosquitoes of Central America and Mexico. J. Am. Mosq. Contr. Assoc. 6, 7-34 (1990).

73. Sallum, M. A. M. \& Forattini, O. P. Revision of the Spissipes Section of Culex (Melanoconion) (Diptera: Culicidae). J. Am. Mosq. Contr. Assoc. 12, 517-600 (1996).

74. Barcode of Life - Identifying Species with DNA Barcoding. Available at: http://www.barcodeoflife.org/. (Accessed: 18th May 2014).

75. Loaiza, J. R. et al. Novel genetic diversity within Anopheles punctimacula s.l.: Phylogenetic discrepancy between the Barcode cytochrome c oxidase I (COI) gene and the rDNA second internal transcribed spacer (ITS2). Acta Trop. 128, 61-69 (2013).

76. Tamura, K. et al. MEGA5: Molecular evolutionary genetics analysis using maximum likelihood, evolutionary distance, and maximum parsimony methods. Mol. Biol. Evol. 28, 2731-2739 (2011).

77. GenBank - The genetic sequence database: collection of all publicly available DNA sequences. Available at: http://www.ncbi.nlm.nih. gov/genbank/. (Accessed: 10th July 2015).

78. Jansen, F. \& Oksanen, J. How to model species responses along ecological gradient - Huisman-Olff-Fresco models revisited. J. Veg. Sci. 24, 1108-1117 (2013)

79. Whittaker, R. H. Evolution of species diversity in land communities. Evol. Biol. 10, 1-67 (1967).

80. Gotelli, N. J. \& Colwell, T. K. Quantifying biodiversity: procedures and pitfalls in the measurement and comparison of species richness. Ecol. Lett. 4, 379-391 (2001).

\section{Acknowledgements}

We are grateful to Oris Acevedo, Belkis Jimenez and Hilda Castañeda for logistical support at BCI; Eyda Gomez for helping managing the project logistics and for technical guidance; Mauricio Quintero, Anel J. Duncan, Denis Lezcano, Gaspar Ho, Eric Alvarez, Philip Davis, Eric Rodriguez and Apolonio Valdez for field assistance. This work was financed in part by the Environmental Protection Agency- Smithsonian Tropical Research Institute research grant DW33-92296801-0 "Mosquito Species Diversity and Landscape Change" to MJP. DNA barcode sequencing was supported by a grant from the EPA to the U.S. National Museum of Natural History (DSGC 676010) to Doctor Robert Robbins and DHF. The Secretariat for Science, Technology and Innovation of Panama (SENACYT), through the research grants GRID15-IP-002 and IDDS15-047 and the National System of Investigation (SNI), supports research activities by JRL. GZL is financially supported by the São Paulo Research Foundation BIOTA Fapesp Program (FAPESP, Grant no. 2014/09774-1 and FAPESP, Grant no. 2015/096696). The funders had no role in study design, data collection and analysis, decision to publish, or preparation of the manuscript. This research was performed under a Memorandum of Understanding between the Walter 
Reed Army Institute of Research and the Smithsonian Institution, with institutional support provided by both organizations. The published material reflects the views of the authors and should not be construed to represent those of the Department of the Army or the Department of Defense.

\title{
Author Contributions
}

The study was designed by J.R.L., O.I.S., J.P. and M.J.P., and conducted by J.R.L., M.R., J.R.R., and J.P. Intensive mosquito sampling collection were undertaken by J.R.L., M.R., L.C.D., J.R.R., J.P., G.E., and D.F. Morphological mosquito species identification was carried out by J.R.L., J.R.R., and J.P. Molecular species confirmation was done by J.R.L. and L.C.D. Data analysis and graph preparation were done by G.Z.L. and J.R.L.; J.R.L. and G.Z.L. wrote the first draft and O.I.S., L.C.D., J.R.R., M.R., J.P., G.E., L.D.K., D.F., and M.J.P. contributed substantially to the final version of the manuscript.

\section{Additional Information \\ Supplementary information accompanies this paper at doi:10.1038/s41598-017-07476-2}

Competing Interests: The authors declare that they have no competing interests.

Publisher's note: Springer Nature remains neutral with regard to jurisdictional claims in published maps and institutional affiliations.

\begin{abstract}
(c) (i) Open Access This article is licensed under a Creative Commons Attribution 4.0 International License, which permits use, sharing, adaptation, distribution and reproduction in any medium or format, as long as you give appropriate credit to the original author(s) and the source, provide a link to the Creative Commons license, and indicate if changes were made. The images or other third party material in this article are included in the article's Creative Commons license, unless indicated otherwise in a credit line to the material. If material is not included in the article's Creative Commons license and your intended use is not permitted by statutory regulation or exceeds the permitted use, you will need to obtain permission directly from the copyright holder. To view a copy of this license, visit http://creativecommons.org/licenses/by/4.0/.
\end{abstract}

(C) The Author(s) 2017 